\title{
CULTURA CÍVICA, DESIGUALDAD Y EQUIDAD EN CHILE
}

\author{
RAÚL URZÚA
}

\section{INTRODUCCIÓN}

La economía chilena experimenta desde hace ya diez años una continuidad de altas tasas de crecimiento del producto inéditas en nuestra historia. Ellas han ido acompañadas de una drástica disminución de la desocupación y de una caída de la inflación a niveles de un dígito. A lo anterior hay que agregar mejoramientos indudables en las condiciones materiales de vida de la gran mayoría de la población, incluyendo en ella a estratos que caen actualmente bajo la línea de pobreza. Por otro lado, los gobiernos de los presidentes Aylwin y Frei Ruiz-Tagle han tenido éxito en la disminución la proporción de los indigentes (Aylwin) y pobres (Frei).

Los anteriores son éxitos importantes de un modelo económico que tiene como eje la economía de mercado y su apertura a los mercados mundiales, pero que aplica pragmáticamente una estrategia que combina una fuerte ingerencia del sector privado de la economía con la mantención en manos del Estado de actividades económicamente estratégicas, un intento por redefinir los mecanismos de regulación del conjunto de las actividades económicas y un conjunto de políticas sociales destinadas a fortalecer la posición de los estratos más pobres a fin de lograr una mayor igualdad de oportunidades. El lema que resume la meta de la estrategia es el "desarrollo con equidad".

Sin embargo, no todo es éxito. Ya a los comienzos de los años noventa algunos empezaron a hacer notar que el sistema educacional chileno, a pesar de haber alcanzado niveles de cobertura prácticamente total en el nivel básico y muy alto en el medio, con el consiguiente aumento en el promedio de años de escolaridad, acusaba serias debilidades en cuanto a sus metas y a la eficacia, eficiencia y efectividad de sus programas.

Sucesivos informes del ministerio de educación, de la Comisión de Educación de la UNESCO y de la Comisión Brunner identificaron los puntos débiles y señalaron las formas de eliminarlos. Desde una perspectiva más amplia, otros han hecho ver que las profundas diferencias en la calidad de ia educación impartida por las escuelas y los colegios particulares pagados, los municipalizados y los públicos han hecho que los progresos educacionales 
cuantitativos puedan ir unidos a un aumento en la desigualdad social, centrando las oportunidades para el éxito y la movilidad social en los que tienen acceso a los primeros. Aunque esta no deja de ser, por el momento, una hipótesis, ella parece bastante plausible.

Por otro lado, hay también indicadores de que el acceso a la salud continúa siendo muy desigual y que el sistema de las ISAPRES no ha contribuido a hacerlo más equitativo.

$\mathrm{Si}$ a esto se agrega la inquietud por los efectos mantenedores de la desigualdad del sistema de las asociaciones de fondos previsionales (AFPs), basados en el ahorro individual, pareciera que una parte importante de las políticas sociales están contribuyendo a reforzar la desigualdad frente a la enfermedad y la vejez.

A lo anterior vienen a agregarse los datos dados a conocer recientemente por MIDEPLAN de la encuesta Cassen 1994. Aunque aún incompletos, ellos muestran dos hechos inquietantes. El primero es la mantención de los niveles de indigencia entre 1992-1994. A pesar de ser la lucha contra la pobreza un objetivo prioritario de los gobiernos democráticos elegidos después del gobierno militar, el porcentaje de hogares indigentes disminuyó sólo del 7,2 al 6,6 en el total nacional entre esas dos fechas. Más grave aún, en las areas rurales el porcentaje de indigentes aumentó levemente, del 8,1 al 8,4 por ciento. Este resultado, inesperado para el actual gobierno, pareciera estar indicando que se ha llegado a un nucleo duro de la pobreza difícil de eliminar con políticas de corto plazo.

El segundo hecho inquietante es la tendencia que muestra la participación del ingreso de los hogares en el ingreso total, por deciles de ingreso familiar per cápita. Las cifras dadas a conocer hasta ahora muestran que entre 1992 y 1994 no sólo no hubo una disminución de la desigualdad entre los estratos más pobres y los más ricos, sino que los siete primeros deciles, sin excepción, disminuyeron levemente su participación en el ingreso total, mientras que los deciles más altos aumentaban, también levemente, su participación. La variación porcentual 94/92 muestra que mientras que el ingreso promedio de los hogares a nivel nacional aumentó en $6,4 \%$ y el de los deciles 8 y 9 lo hizo al $8,6 \%$ y $8,7 \%$, respectivamente. el decil 1 disminuyó su participación en $-3,9 \%$. Aunque el decil 10 porcentualamente aumentó menos que otros su participación, el aumento fue suficiente para aumentar su distancia respecto a los que lo siguen y a hacer que el ingreso promedio de los hogares del decil 10 sea ahora 40 veces mayor que el del decil l, en vez de las 36 veces que lo era en 1992.

En suma, el éxito económico ha sido compatible con un aumento del ingreso per cápita en todos los deciles de ingreso, salvo aquel que corresponde a los indigentes, así como con la ampliación de la distancia en el ingreso promedio de los hogares más pobres y los más ricos.

Más allá de los comentarios de prensa, sea justificando los resultados, sea utilizándolos para poner en duda el modelo económico que sigue el país. hay indudablemente factores económicos, sociales, políticos, culturales, psicosociales. organizacionales y de gestión que es necesario examinar para decidir sobre como eliminar la pobreza extrema, disminuir las desigualdades en la distribución del ingreso y aumentar la igualdad de oportunidades. En definitiva, la pregunta es como avanzar conjuntamente hacia un más alto crecimiento económico y una mayor equidad. 
El objetivo de este artículo es examinar algunos aspectos de nuestra cultura cívica que afectan y condicionan los esfuerzos por lograr un desarrollo con equidad en nuestro país. La tesis que se procurará examinar es que la cultura chilena ha demostrado tradicionalmente una gran tolerancia a la desigualdad social, la que ha resultado compatible con pautas de movilidad e integración sociales resultantes más bien de la invitación o el patrocinio de las elites políticas y sociales que de la competencia. Como consecuencia y expresión de lo anterior, los mecanismos y procesos de participación social y política han sido más bien promovidos desde arriba que el resultado de presiones desde la base. Se examinará también la tesis del predominio de grupos e intereses corporativos por sobre normas sociales que rijan las relaciones entre grupos y las consecuencias que ese predominio habría tenido en las políticas, la aplicación efectiva de las normas jurídicas y la participación social. - Después de proponer algunas consideraciones sociológicas fundamentales sobre las cuales se apoya la argumentación. el análisis interpretativo de algunas características de nuestra estructura social y del sistema político hasta antes del gobierno militar intentará hacer plausible, si bien no necesariamente probar de manera irrefutable, esas tesis. Planteado lo anterior, se analizará algunas transformaciones ocurridas durante los últimos veinte años tanto en la sociedad como en el sistema político y la cultura cívica. Más concretamente y sólo de manera exploratoria, se tratará de identificar los cambios ocurridos en el sistema de estratificación y movilidad social, en los órganos de representación y participación política y en las demandas y formas de participación. Con los antecedentes anteriores se planteará algunas hipótesis acerca de las alternativas probables de evolución de nuestra sociedad y los desafíos que ellas conllevan para el logro de una mayor equidad.

\section{ALGUNAS CONSIDERACIONES SOCIOLÓGICAS GENERALES.}

Antes de examinar y proponer una interpretación del caso chileno es útil hacer algunas consideraciones sociológicas generales, basadas en principios de amplia aceptación y que han pasado a ser reconocidos como supuestos para la sociología contemporánea.

1. - La primera de ellas es que no hay evidencia histórica de sociedades totalmente igualitarias. Siendo la desigualdad una constante, no lo son los criterios de desigualdad ni la forma y el grado en que la desigualdad en un determinado atributo o característica determina o condiciona otras desigualdades. Para citar un ejemplo conocido y en boga en estos momentos, aunque en todas las sociedades ha habido un cierto grado de desigualdad entre los roles masculino y femenino, hay marcadas diferencias históricas y comparativas en la magnitud y las esferas que cubre esa desigualdad.

Algo análogo es lo que ocurre en relación con el color de la piel o, más ampliamente, las características raciales. Aunque son pocas las sociedades que están libres de utilizarlas como una forma de discriminar, el carácter de la discriminación es muy variable. En la América anglosajona, por ejemplo, el principio fundamental que sirve culturalmente para definir razas es el de herencia biológica: aquel que desciende de negros será siempre negro, como siempre será indio americano el descendiente de indios americanos y asiático el descendiente de asiáticos. En la América hispano-lusitana, el criterio es más bien social y cultural: dos personas con el mismo componente étnico-racial serán vistos socialmente como blancos o no blancos según su posición social y sus patrones de vida ${ }^{1}$. Los estudios del

\footnotetext{
'Sobre este punto véase, entre otros, Harris, Marvin, 'Patterns of Race in the Americas'. New York: Walker and Company. 1964.
} 
eminente genetista Cavalli-Sforza en Stanford y de André Langaney en París y Ginebra sobre el tema han confirmado más recientemente las débiles bases biológicas del concepto mismo de raza: el hombre tendría un origen único, alrededor de hace 100.000 años, en alguna parte entre el Africa Oriental y el Cercano Oriente y las diferencias entre razas se deberían a adaptaciones a ecosistemas. Por otro lado, el análisis de los sistemas sanguíneos, de las defensas inmunológicas y del genoma humano han llevado a demostrar que, salvo los verdaderos gemelos, los seres humanos son genéticamente diferentes, cada individuo es único. Paradojalmente, la biología muestra también el extraordinario parentesco entre todas las poblaciones ${ }^{2}$.

Este segundo ejemplo sirve para mostrar, además, como desigualdades supuestamente biológicas y, en general, todas las desigualdades, son, en definitiva, desigualdades sociales construidas a partir de una u otra característica individual a la cual se le atribuye consecuencias socialmente definidas como positivas o negativas. Esto quiere decir que todas las sociedades tienen principios que definen y regulan las desigualdades.

2. - Una segunda consideración general es que esa definición y regulación de las desigualdades se hace, fundamentalmente, en relación con los problemas de coordinación que surgen dondequiera los seres humanos pretenden vivir y reproducirse juntos. En su ya clásico libro sobre el tema, Barrington Moore, ha agrupado esos problemas en tres grandes categorías: el problema de la autoridad, el de la división del trabajo y el de la distribución de los bienes y servicios ${ }^{3}$.

Ninguna sociedad puede sobrevivir sin la definición de procedimientos para definir quien manda y como se accede al poder, quien hace qué cosa y como se distribuyen los beneficios.

Por lo mismo, solucionar de alguna manera esos problemas pasa a ser un imperativo tanto social como moral. De allí que todas las culturas incluyan normas relativas a ellos.

Sin embargo, es claro que en cada sociedad hay formas alternativas posibles de enfrentar esos problemas que satisfacen en mayor o menor grado los intereses, valores o aspiraciones de distintos grupos y personas. Aunque cual de esas alternativas se impone en un determinado momento histórico y su permanencia en el tiempo dependen del poder que tengan los partidarios de una u otra, en todas las sociedades las diversas opciones son justificadas o buscan una justificación ética.

Precisando un poco más el punto anterior, diría que en el ethos de toda sociedad están implícitos, pero internalizados por los miembros de la sociedad, valores, creencias y normas que definen: cuales son las desigualdades relevantes socialmente, como se relacionan ellas con la solución de los problemas ligados con la coordinación social. como se mantienen las desigualdades en el tiempo y el grado y los límites dentro de los cuales las desigualdades son consideradas legítimas o, al menos, toleradas.

Una parte importante de las definiciones del ethos social en lo que se refiere a la

\footnotetext{
2 Para discusiones al alcance de no especialistas de este tema véase el númoro especial dedicado a la "ciencia de la raza". 6. 'Discover', Noviembre, 1994; también 'Sciences et Avenir'. Febrero, 1992.

${ }^{3}$ Moore, Barrington Jr., 'Injustice. The Social Bases of Obedience and Revolt', White Plains. New York: M. E. Sharpe. Ir. 1978.
} 
desigualdad se refieren a los procesos de discriminación y exclusión social y cultural presentes en todas las sociedades. Así como no hay sociedades totalmente igualitarias, no hay tampoco sociedades en las cuales no existan normas que permitan distinguir entre "nosotros" y "los otros". Son esas normas las que transforman diferencias externas en criterios para establecer desigualdades acumulativas y de carácter más general. Es también la tendencia a la exclusión de los otros, los diferentes, la que lleva a que grupos sociales desigualmente colocados en la estructura de poder, en la división del trabajo y en el acceso a bienes y servicios, desarrollen subculturas propias, formas de distinción y al mismo tiempo de integración.

Creación y reproducción de desigualdades, afirmación de identidades y de diversas formas de distinción, creación de subculturas que legitiman y dan continuidad a esas distinciones, al mismo tiempo que excluyen a los que no pertenecen a ellas ${ }^{4}$, son procesos sociales presentes en todas las sociedades conocidas.

Tomadas en su conjunto, esas pautas son las que definen la estructura del poder y el sistema de clases de una sociedad. Sin embargo, ellas no se expresan sólo a niveles estructurales y macro sistémicos sino que constituyen y moldean la vida cotidiana, la forma como nos relacionamos unos con otros, nuestras prácticas y nuestros hábitos, nuestro sentido de lo que es justo o injusto, tolerable o intolerable. Vistos desde la perspectiva planteada aquí, tanto la una como el otro son parte inseparable del ethos de toda sociedad, aunque ciertamente no coinciden totalmente con él.

3. - Pero una sociedad no sería más que un agregado de grupos heterogéneos si no es capaz de generar, junto con normas propias a cada uno de ellos, otra que afirmen la igualdad de todos los habitantes y definan una identidad nacional. De hecho, bien puede decirse que existe una sociedad (no "la" sociedad genérica) sólo cuando existe un sentido de identidad común y una aceptación, mínima y variable en el tiempo de los arreglos sociales que evita el estado de guerra civil permanente. Por consiguiente, es posible afirmar que la historia de toda sociedad es la dialéctica constante entre las tendencias a la desigualdad y la exclusión y la lucha por la igualdad.

Una parte importante de esos arreglos son reglas que regulen las relaciones intergrupos y entre individuos anónimos. Las reglas que rigen las relaciones de mercado y la participación en las decisiones públicas constituyen las más centrales, pero también forman parte de ellas las que regulan las interacciones en lugares de uso público y el uso que se hace de bienes públicos.

Tanto las reglas intra-grupos como extra-grupos suponen y se apoyan en el reconocimiento de una igualdad esencial que exige reconocer a los iguales los derechos que cada uno se reconoce a sí mismo. Las normas extra-grupo y universales presumen el reconocimiento de derechos humanos fundamentales, los que a su vez suponen aceptar como seres humanos a los extraños, los extranjeros, los que no son "nosotros".

Más allá de las declaraciones formales, la historia y la actual situación mundial muestran que no es fácil llegar a ese reconocimiento y que estamos aún lejos de que llegue a ser realidad en los ethos operantes en las diversas sociedades, incluso aquellas que iniciaron el

${ }^{4}$ Formas de hablar, de vestirse, gustos, tipos de actividades. en general, estilos de vida. 
proceso que ha llevado a esos reconocimientos formales. Sin embargo, es claro que, como ha reconocido la sociología desde sus orígenes, las sociedades varían en la medida en que ellas respetan normas universales en vez de adherir sólo a normas particularistas. Recuérdese que ésta fue una de las "variables-pautas" de Parsons, válidas para comparaciones tanto en sociedades particulares como entre sociedades, aplicadas simplístamente por los sociólogos de la modernización de la década del sesenta.

4.- A partir de las consideraciones anteriores procuraré ahora dar una mirada sintética a la desigualdad social en Chile. Para esto. más que en desigualdades objetivas pondré énfasis en como se ha expresado y cristalizado institucional y políticamente la dialéctica igualdad-desigualdad presente en todas las sociedades. Apoyándome en los tres problemas de "coordinación que enfrenta toda sociedad a que se hizo alusión más arriba", procuraré dar una visión de aspectos que me parecen relevantes de la evolución de los arreglos políticoinstitucionales, es decir, de las prácticas y normas efectivamente vigentes.

\section{EL PASADO OLIGÁRQUICO}

Una primera cosa que hay que recordar es el carácter oligárquico que ha tenido durante gran parte de su historia la sociedad chilena. carácter que encuentra sus raíces en el siglo XVII y que alcanza su consolidación en el siglo XVIII, cuando logra hacer frente con éxito al reformismo borbónico ${ }^{6}$.

Es carácter oligárquico del poder se daba en una sociedad que, durante el siglo XIX y los primeros años de este siglo, era predominantemente rural, tanto por la distribución geográfica de su población como por el tipo de relaciones sociales entonces predominante. A su vez, la división del trabajo y la estratificación social eran comparativamente simples, caracterizándose por la existencia de una clase de propietarios agrícolas, mineros, comerciantes y financistas con una gran coincidencia de intereses económicos y ligados por estrechos vínculos familiares; por un pequeño número de profesionales y burócratas, ubicados en una posición intermedia, y poruna gran masa trabajadora de campesinos, artesanos, sirvientes y algunos pequeños núcleos obreros, prácticamente sin organización y ligados por vínculos de dependencia personal con los miembros de la clase propietaria.

En concordancia con esas características estructurales, el sistema político imperante hasta comienzos de este siglo, suponía que una minoría participaba en el ejercicio del poder y reservaba la pertenencia al estrato con participación política y, por consiguiente, la posibilidad de ser miembros de la élite gobernante, a los grandes propietarios agrícolas, financistas, mineros y algunos profesionales e intelectuales estrechamente ligados a ellos. Los partidos políticos de la época correspondían a esa estructura oligárquica del poder. Giraban ellos en torno a uno o más miembros notables de la élite política -que era también la élite social y económica- y prácticamente ignoraban discusiones ideológicas sobre intereses contrapuestos en lo económico social. Representaban a una clase social que no había sido aún desafiada por otras clases y en la cual no surgían todavía diferencias sectoriales de importancia. La ausencia de intereses económico-sociales claramente contrapuestos conducía también a que no existiesen grupos de interés propiamente tales y a que la influencia política se ejerciera

${ }^{5}$ Quién manda, quién hace qué cosa y cómo se distribuyen los beneficios.

'Jocelyn-Holt Letelier, Alfredo, 'La Independencia de Chile', Madrid: Editorial Mapfre, 1992) 
individualmente por miembros de la élite sobre los que tenían vínculos de subordinación y dependencia con ellos.

En una sociedad con esas características no es de extrañar que ni las desigualdades objetivas entre las, básicamente, dos clases que la constituían, ni la desigualdad en cuanto a las oportunidades de los miembros de una y otra clase para desarrollar sus capacidades humanas, fuesen seriamente cuestionadas. Los pocos, débiles y siempre no exitosos cuestionamientos provenían de miembros de la misma élite y no encontraban apoyo social de importancia?.

Por un lado, el sistema particularista de relaciones entre las clases, de origen en la hacienda pero generalizado a la sociedad toda, como mostrara hace más de treinta años José Medina Echeverría, creaban vínculos personales entre miembros de una y otra clase que han estado presente hasta bien avanzado el presente siglo. Por el otro, las familias oligárquicas habían desarrollado y perfeccionado en el tiempo todo un conjunto de hábitos ${ }^{8}$, que cumplían eficazmente la función de asegurarles su distinción respecto a las otras clases, reafirmar su propio sentido de pertenencia y excluir a quienes no definían como sus iguales, o no querían aceptar como tales. El arribismo social era sancionado con el lapidario apelativo de siútico que condenaba al que lo sufría a permanecer en una especie de "tierra de nadie". rechazando su pertenencia a los estratos medios y siendo rechazados por aquellos a cuya clase le gustaría pertenecer.

Sin embargo, lo anterior no significaba que hubiese una total falta de movilidad social. Los grupos oligárquicos de origen colonial estuvieron siempre selectivamente abiertos a los candidatos a pertenecer a ellos que, además de tener los medios económicos suficientes, eran capaces de adoptar los patrones de vida que ellos compartían y no cuestionaban los arreglos sociales que hacían posible la dominación oligárquica. Durante la segunda mitad del siglo pasado, los más exitosos en lograr la incorporación al grupo dominante fueron los migrantes o hijos de migrantes de europeos, seguidos por miembros de las clases altas provincianas.

En suma, las relaciones sociales institucionalizadas durante el siglo XIX se caracterizaban no sólo por desigualdades objetivas, sino por el predominio sin contrapeso de un ethos que legitimaba la desigualdad y no daba cabida a la presencia de normas y relaciones sociales universalistas. De allí que la responsabilidad por crear un sentido de unidad nacional e imponer al menos un mínimo de normas universales recayera en el estado. La creación y codificación temprana de un cuerpo de normas constitucionales y legales ${ }^{7}$, y el énfasis dado a la educación son intentos republicanos por crear un conjunto de normas que fueran más allá de las que el ethos oligárquico era capaz de producir por sí mismo.

\section{2.- LA POLÍTICA DE NOTABLES EN CRISIS}

La situación de predominio oligárquico, apoyada en una participación en el poder político restringida sólo a una minoría de los nacionales empiezà a quebrarse en el primer

\footnotetext{
7 Piénsese, por ejemplo, en Francisco Bilbao y Santiago Arcos. frustrados propiciadores de la Sociedad de la Igualdad

${ }^{*}$ En el sentido que da Bourdieu a habitus.

${ }^{9}$ Constitución de 1933 y Código Civil.
} 
cuarto de este siglo, a raíz de la mayor complejidad que adquieren nuestra economía y estructura social. Por un lado, la población pasa a ser predominantemente urbana, con la consiguiente disminución del empleo agrícola y el aumento de las ocupaciones urbanas en la construcción, el comercio y los servicios. Por otro lado, las situaciones de clase se hacen más complejas: latifundistas y comerciantes ven surgir un poderoso nucleo de industriales que cuenta con el beneplácito y apoyo del Estado, la clase media dependiente (empleada) se duplica en un lapso de treinta años, el proletariado se expande primero para quedar estacionario después, los trabajadores por cuenta propia en el comercio y los servicios crecen considerablemente, etc.

El aumento en la diferenciación social y el surgimiento de nuevas situaciones de clase se traducen en importantes cambios en el sistema político. Ellos se pueden resumir en los siguientes puntos:

a) Ampliación de la base de participación política: el electorado crece del 7,4\% de la población en 1925 a $10,3 \%$ en $1938,20,5 \%$ en $1958,34,8 \%$ en 1964 y $36,1 \%$, para la última elección presidencial antes del golpe de Estado de las Fuerzas Armadas;

b) Surgimiento de nuevos partidos políticos que intentan dar expresión a los partidos de la clase obrera urbana, mientras que los partidos tradicionales deben empezar a responder a las demandas económico-sociales planteadas por el recientemente ampliado electorado.

El conflicto empieza a seguir las líneas de quiebre de las distintas clases sociales;

c) Gradual pero progresivo movimiento de las preferencias electorales hacia la izquierda;

d) Surgimiento de organizaciones de obreros y empleados, transformación de los antiguos"ateneos" oligárquicos ${ }^{10}$ en asociaciones destinadas, juntos con todas las de creación más reciente integradas a la Confederación de la Producción y el Comercio, a defender los intereses de las diversas fracciones empresariales;

e) Ampliación del papel y las funciones del Estado, independientemente de cual fuere la doctrina oficial imperante: reorganización del Estado para poder administrar y utilizar los ingresos provenientes de los impuestos pagados porlas empresas extranjeras; rol activo del Estado en apoyo de la industrialización del país.

Vale la pena destacar que esos cambios en el papel y las funciones del Estado contribuyen por su lado a complejizar la estructura social al lievar a la creación de nuevas clases sociales: un empresariado industrial, una clase media dependiente y un proletariado industrial más extensos.

\section{LA CONTINUIDAD DENTRO DEL CAMBIO}

Aunque los cambios que se ha reseñado brevemente son importantes, ellos no significan un quiebre fundamental con el pasado. Desde luego, el surgimiento de nuevos grupos de

"S. N. A., SOFOFA. 
poder económico no se traduce en una pérdida total del poder de los grupo que in tradicionamente. Un ejemplo de esto es que los grandes propictarios agrice ajustarse a esos cambios y mantener una estructura de tenencia de la therra que lin mantener su influencia económica, política y social hasta los gobiemos de Frei Montai... Allende.

Los mecanismos que permitieron mantener ciertos rasgos del pasado ene la muevi estructura social y evitar cambios bruscos en la élite dirigente fueron múltiples.

Uno de ellos es el inteligente manejo por parte de la "clase alta tradicional", es decir, del grupo de familias de mayor prestigio y con el monopolio del poder social (que anteriormente constituían la oligarquía) de los recursos simbólicos a su disposición: el acceso a los círculos sociales más exclusivos, el otorgamiento de amistad y deferencia, los entrecruzamientos matrimoniales, van cooptando paulatina pero seguramente a los miembros de las nuevas elites políticas y económicas con orígenes en los estratos medios.

A esta asimilación social se une la integración económica. La compra de fundos por parte de industriales y comerciantes, tanto por razones de prestigio social como para aprovechar las ventajas del sistema tributario agrícola, así como, por el otro lado, la incorporación de algunos empresarios agrícolas al mundo de las finanzas, fueron vínculos que ligaron los intereses económicos de la nueva y la antigua clase dirigente.

La consecuencia de esto es que si bien los partidos que buscaban representar los intereses de los estratos medios y el proletariado participaban- a veces controlaban-las posiciones de autoridad en el aparato institucional del Estado, las personas que ocupaban esas posiciones terminaron asemejándose cada vez más a los líderes de los partidos políticos de derecha.

Por último, es necesario recordar que los partidos de derecha mantuvieron hasta 1973 un apoyo electoral que fluctuaba alrededor del $30 \%$.

Todo lo anterior ocurre en momentos en que el Estado ha pasado a desempeñar un papel fundamental en la conducción económica del país y en que, por consiguiente, ía conquista del poder en él, o el contacto con quienes lo ejercen, pasa a ser condición casi indispensable para lograr algún cambio o alguna reivindicación.

En suma, la diferenciación estructural y los cambios políticos ampliaron y diversificaron las posiciones en la cumbre del poder político, económico y social, pero no llevaron a una circulación de las elites, sino más bien a la fusión de nuevas y antiguas elites.

Esta integración en la cumbre trajo como consecuencia la gran concentración del poder económico que pusieron de manifiesto la serie de estudios realizados durante la década de los sesenta.

\section{INTEGRACIÓN DESDE ARRIBA Y NUEVO CLIENTELISMO}

La integración desde arriba tuvo un efecto político que interesa destacar: el surgimien- 
to de una nueva forma de clientelismo. En esta forma remozada del antiguo sistema, los políticos y toda una gama de intermediarios (los "contactos" o las "cuñas") servían de nexo entre los distintos grupos y el Estado todopoderoso. El intermediario tenía poder no por sí mismo sino por su conocimiento de con quien hablar a fin de obtener que se haga algo. Este intermediario, fuese o no político (muchas veces era un burócrata de rango medio), pasó a desempeñar el papel que antes cumplían los patrones o los caciques locales, pero el cliente ya no era una persona o una masa desorganizada de personas, sino asociaciones u organizaciones que utilizan al intermediario en la medida en que este les es útil para obtener prebendas con el Estado.

Una consecuencia importante de este nuevo clientelismo y de la integración desde arriba fue poner límites a esta última, como lo demostró la imposibilidad existente por mucho tiempo de organizar al campesinado. Otra, de más largo alcance en sus efectos, es que llevaba a una integración fraccionada. Las distinciones legales en cuanto a privilegios y recompensas que existían entre empleados y obreros, el particularismo que caracterizaba al sistema de seguridad social, el fraccionamiento del movimiento obrero, la indiferencia de los obreros urbanos por la suerte de sus "compañeros de clase en el campo", etc., son manifestaciones del fraccionamiento que produce una integración desde arriba.

El resultado final fue un sistema político caracterizado por la presencia de una poderosa élite de origen pluriclasista pero predominantemente de clase media, que controlaba las posiciones claves del Estado y tenía recursos suficientes como para afectar el destino de grupos e individuos, cualquiera que sea la clase a que pertenecieran. Esa élite mantenía una serie de relaciones particularistas con sus clientes electorales, basadas en lealtades partidarias, gremiales o personales, tratando de satisfacer sus demandas específicas a fin de mantenerlos como clientes y procurando siempre ampliar el número de estos. A su vez, todos los grupos sociales orientaban sus demandas hacia el Estado y esperaban que este intervenga en su favor.

Dentro de ese contexto de integración y promoción promovida, de debilidad de la sociedad civil y de particularismos corporativistas la educación pública y gratuita es vista por los distintos estratos de la población como el canal de movilidad social de carácter universal abierto a todos.

Para los efectos de nuestra discusión aquí la conclusión que es necesario subrayar es que nuestro sistema político evolucionó en un sentido que reforzaba la subsistencia de las normas particularistas y que buscaba la mayor igualdad de manera gradual y tratando de evitar quiebres bruscos en el sistema.

\section{5. - LA CRISIS DEL SISTEMA DE CLIENTELAS}

Un sistema como el que hemos descrito se basa, en definitiva, en la debilidad de los grupos utilizados como clientes. Entra en crisis cuando la población organizada crece cuantitativamente y las organizaciones aumentan su cohesión interna.

Los dos últimos gobiernos democráticos antes del pronunciamiento militar contribuyeron al aumento espectacular que experimentaron las organizaciones sociales. Al mism: 
tiempo, el intento del segundo de introducir cambios estructurales revolucionarios y el alineamiento de las organizaciones de la sociedad civil con una u otra de las partes en conflicto contribuyeron a dar mayor cohesión a esas organizaciones. Por otro lado, a mayoría de los partidos que apoyaban al gobierno de Allende aceptaba la posición de que ellos interpretaban los intereses "reales" de los proletarios y no podían sino rechazar como "falsa conciencia", cualquier desacuerdo que existiera entre las demandas del proletariado en general y de las organizaciones obreras, y la forma como ellos definían la situación. Esta posición llevó a la polarización política que terminó poniendo fin a la democracia y dejando sin arena en la cual expresarse y aplicar el sistema político de clientelas.

\section{LA SECUELA DEL ETHOS TRADICIONAL EN EL RÉGIMEN MILITAR}

Desde la perspectiva que nos interesa aquí, el quiebre de la democracia y el régimen militar autoritario fue visto por muchos como consecuencia de la ruptura de los consensos básicos en que se había apoyado nuestro sistema democrático. El análisis que se ha hecho aquí no niega lo anterior, pero lleva a sostener que los atentados a los derechos humanos cometidos durante el régimen militar no se explican sólo por la coerción sino también por la presencia de un ethos fuertemente enraizado que favorece el particularismo, desconfía de las normas universales y las relaciones impersonales tanto en la vida privada como la pública y termina por justificar o dejar indiferente frente a la desigualdad.

Algunos ejemplos servirán para ilustrar el punto. A pesar de la evidencia existente y la notoriedad con que se violó los derechos humanos durante ese período, muchos negaron la existencia de esas violaciones o las disculparon como un consecuencia inevitable de una " guerra interna". La indignación moral por la violación de los derechos humanos no fue compartida por toda la clase política y estuvo subordinada al color político de quien sufrió la violación. Por otro lado, las encuestas de opinión pública de los ochenta muestran que la mayoría de la población tenía conciencia de que existia un problema de derechos humanos en el país, pero sólo una minoría lo mencionaba como un probiema grave o como algo que estuviese afectando seriamente la unión de los chilenos. Si bien la poca importancia dada a la violación de ese derechos por los encuestados de bajo nivel socioeconómico podría explicarse por la gravedad que tenían para ellos los problemas de empleo, ingreso y seguridad en las poblaciones, esa explicación no parece plausible para los de posicion socioeconómica más alta y de mayor nivel educacional.

En suma, pareciera que durante el régimen militar no existía en Chile una norma ética socialmente aceptada que hiciera indignarse moralmente frente a las violaciones de los derechos de quienes no son parte del "nosotros". La indignación moral frente a ellas con independencia de las características personales de quienes las sufren no se extendió más allá de grupos religiosos, de una parte de las elites políticas e intelectuales del país y de un porcentaje claramente minoritario de la población.

Sin negar el efecto que puede haber tenido la violencia que caracterizó a las relaciones políticas y sociales bajo el gobierno militar, mi tesis es que tanto la violación sistemática de los derechós humanos como la ausencia de una sensación generalizada de "ultraje moral" son un reflejo del particularismo y la desigualdad que ha caracterizado el ethos y la cultura

"La expresión está tomada de Barrington Moore Jr., op. cit 
cívica chilenas. La aparente ausencia, o la debilidad, de una norma social condenatoria de la violación de los derechos humanos de quienes no tienen con nosotros vínculo alguno no sería, si se acepta la tesis que aquí he planteado, sino la expresión aberrante y patológica de un patrón de relaciones sociales que se expresa también en el predominio de los intereses corporativos por sobre los generales, en la falta de ética en los negocios, en la búsqueda de prebendas y privilegios sea legalmente, sea ignorando la ley o contra ella, en el contraste entre la cortesía doméstica y la violencia y agresividad en la calle, etc.

Al particularismo se une la desigualdad social. Usando una expresión de Rancière ${ }^{12}$, podríamos decir que en Chile ha predominado una "socialidad de la desigualdad" que se expresó durante el gobiemo militar en un aumento de las diferencias en los niveles de vida de los diversos estratos sociales, en un tratamiento discriminatorio en contra de los trabajadores y en favor de los empresarios y empleadores, en el agravamiento de la segregación ecológica entre clases y estratos sociales, en la mayor desigualdad de oportunidades educacionales, en las restricciones a la participación política y en el cierre de canales de movilidad social tradicionales en el pais, sin su total reemplazo por otros.

\section{¿HACIA DONDE VA NUESTRA CULTURA CÍVICA?}

La vuelta a la democracia ha significado heredar no sólo un modelo económico, sino también sus consecuencias socioculturales y los remanentes de un ethos y una cultura cívica que encuentra sus orígenes aún antes de que Chile se constituyera en un Estado-nación.

Adaptando a nuestros propósitos las definiciones propuestas por Albala-Bertrand de dos tipos polares de cultura cívica, la "tradicional" y la "pluralista"l3 puede postularse que la cultura política chilena que hizo crisis con el golpe de estado del 11 de Septiembre de 1973 se aproximaba al polo "tradicional" y tenía todavía muchos de los rasgos siguientes:

En el orden normativo: aceptación y respeto de normas sociales y éticas ligadas a situaciones particulares, en vez de normas de aplicación universal (particularismo normativo); desigualdades sociales culturalmente legitimadas;

En el orden político: partidos ideológicos-vanguardistas o partidos clientelísticos; élites políticas fuertes e interconectadas; poca circulación de las élites; poder partidario centrado en las élites de los partidos; propuestas políticas totalizantes de cambios estructurales; alto nivel de conflicto político;

En el orden económico: relaciones capital-trabajo conflictivas por falta o no respeto de mecanismos de regulación de conflictos; expectativas empresariales de corto plazo; búsqueda de proteccionismo estatal.

En el otro extremo, el de la cultura pluralista, estaría aquella a la cual se aproximan, en mayor o menor grado y de formas diversas, las culturas de sociedades con larga tradición de ciudadanía política, económica y social y cuya adopción en regímenes democráticos más

\footnotetext{
12 Rancière, Jacques, "Los sentidos de la Democracia", en Alvayay, R. y C. Ruiz, compiladores, 'Democracia y Participación Santiago. CERC, 1988 , pps. $45-65$.

${ }_{13}$ Albala-Bertrand, Luis, "Li Consolidación Democrática como Objetivo Cultural". en L. Albala-Bertrand (coordinador), "Cultura y Gobernabilidad Democratica, Montevideo: UNESCO' Ediciones Imago Mundi. 1992.
} 
nuevos podría favorecer la legitimidad, consolidación y gobernabilidad a largo plazo de la democracia.

En forma típico-ideal, esa cultura cívica pluralista estaría caracterizada por:

En el orden normativo: aceptación y respeto de normas éticas universales; igualdad real y no sólo formal ante la ley; adecuación del derecho a los cambios sociales y culturales; igualdad y solidaridad como valores reconocidos y estimulados social y legalmente;

En el orden político: conflictos sociales y políticos específicos que no quiebran los consensos básicos; partidos políticos de estructura interna democrática y organizados para agregar intereses; Estado adaptado a los cambios y capaz de orientar las transformaciones societales con eficacia, efectividad y eficiencia; circulación parcial de élites políticas y rotación partidaria en el poder político; utilización de conocimientos científicos y técnicos en la toma de decisiones políticas; deontología de servicio público y responsabilidad ético-política por decisiones;

En el orden económico: expectativas empresariales de mediano y largo plazo; propensión al ahorro y a la inversión; confianza en el mercado e interiorización de normas no contractuales que regulan su funcionamiento; aceptación de división y complementariedad de roles entre el Estado y los empresarios; orientación más generalizada de servicio público en el sector empresarial; existencia y aceptación de mecanismos equitativos de regulación de conflictos capital-trabajo; mayor igualdad en distribución de ingresos y en oportunidades.

Si se acepta que una cultura cívica con las características que se acaba de describir refleja más que la tradicional una profundización de la ciudadanía, en el sentido dado aquí al término, y asegura mejor la gobernabilidad de la democracia, cabe preguntarse si la evolución experimentada por nuestra cultura cívica real la acerca a ese tipo ideal.

La respuesta a esa pregunta requiere de un esfuerzo de sistematización de la información existente acerca de diversos aspectos de esa cultura que está aún por hacerse.

Ese análisis no podrá dejar de tomar en cuenta el impacto de las transformaciones que ha experimentado y está experimentando la economía y la sociedad chilena, así como los efectos culturales probables del modelo económico vigente en el país, y las consecuencias del trauma político provocado por el golpe militar y 17 años de gobierno autoritario sin funcionamiento de la democracia.

Ya me referí a la necesidad de volver a estudiar los cambios macrosociales por los cuales están pasando y probablemente van a pasar nuestras sociedades. Quiero agregar ahora que una de las razones para hacerlo es su influencia probable en la evolución de nuestra cultura cívica. Entre esos cambios merece una mención especial aquí el efecto que tiene sobre la integración y la movilidad social las calidades muy diferentes de educación a que tienen acceso los miembros de diversos estratos. Podría mencionarse también el debilitamiento del movimiento sindical derivado de los cambios en el mercado de trabajo y en la legislación sobre sindicatos, así como el que también parecieran haber experimentado las organizaciones de base. 
En el contexto actual, la hipótesis de que la desigualdad no ha disminuido de manera significativa y que ella sigue siendo una realidad normativamente aceptada parece más plausible que la hipótesis contraria.

En cuanto a los efectos culturales del modelo económico, a título de hipótesis y con la intención de estimular una investigación seria sobre el tema, podría sugerirse lo siguiente:

A) El modelo económico no sólo ha cambiado radicalmente la economía e, indirectamente, la sociedad chilena, sino también la manera como las personas se ven a sí mismas, sus valores e intereses, sus aspiraciones personales. Esos cambios van en la dirección de un modelo de hombre que ha hecho suyas las características del homo oeconomicus que utiliza heurísticamente la economía neoclásica. La transformación de ese tipo ideal en una especie de ideal humano es más notoria en los estratos medios-altos, pero se ha difundido ya a otros estratos sociales que ven en su adopción (al menos externa), en la participación en el consumo conspicuo y en la imitación de los comportamientos y estilos de vida de los estratos más favorecidos una forma de aumentar sus probabilidades de movilidad social ascendente o, por lo menos, una movilidad psicológica.

B) El conocimiento que tione la población del derrumbe de los socialismos reales y los éxitos macroeconómicos de la política económica chilena hacen que el modelo goce de la aceptación de, aparentemente, la mayoría de la población.

C) La falta de crítica al modelo ha sido útil para crear consensos entre gobierno y oposición y ha minimizado los conflictos entre los partidos, pero también ha hecho aparecer a la política como una actividad sin mayores sorpresas y, por lo tanto, menos interesante para la masa ciudadana que no participa activamente en ella. Por su parte, los marginados de los beneficios del modelo, y los que lo rechazan por razones ideológicas o morales, se marginan de toda actividad política o expresan su rechazo de forma atomizada, inorgánica y sin proponer altemativas que puedan ser acogidas por agrupaciones más fuertes.

D) El desarrollo de los medios de comunicación masiva y en especial de la televisión, permite una integración simbólica a los patrones de comportamiento y estilos de vida considerados "modernos" a estratos que enfrentan barreras difíciles de superar para integrarse social y materialmente (por movilidad social y acceso al consumo) a ellos. Esa integración simbólica pareciera hipotéticamente haber tenido dos efectos importantes para esta discusión. El primero sería contribuir a dar credibilidad y a legitimar el modelo económico, tanto directamente en cuanto que poseer un aparato de televisión y ser televidente al igual que los miembros de grupos más privilegiados parecieran producir en sí mismo más un sentimiento de pertenencia que de frustración. El segundo sería reforzar la presión hacia el retiro de lo público para refugiarse en el ámbito de lo privado.

E) Generalizando, la combinación de los factores anteriores pareciera haber conducido a que el chileno valorice más y trate de extender el radio de acción de lo privado por sobre lo público. Esto se expresa no sólo en que se acepta ampliamente la reducción del papel directo del Estado en la producción de bienes y de algunos servicios, sino también en una privatización de las relaciones sociales y en una falta de interés en participar en acciones y movimientos colectivos. 
F) Una parte de la juventud. principalmente de los estratos medios, se margina de lat vida político-partidaria por rechazo al consenso acerca del modelo y busca alternativas en movimientos ecologistas o mediante protestas inorgánicas. Por otro lado, la juventud de los estratos pobres, socjalmente marginada, se margina cultural y psicológicamente de la política.

G) La falta de interés de la masa ciudadana en la política activa refuerza la dirección cupular de los partidos políticos, lo que a su vez genera críticas de las bases partidarias.

Las anteriores son sólo hipótesis que habría que poner a prueba. Más que cuestionar la legitimidad de la política y del régimen democrático, si fueran ciertas estarían señalando una mayor concentración del poder en las élites políticas, el que sería compensado en parte por la reducción del campo de acción directa del Estado y el reforzamiento del empresariado. De comprobarse, estarían indicando que la cultura cívica chilena habría evolucionado en una dirección que llevaría al predominio de la política de élites tecnocráticas más que hacia una democracia pluralista, en la forma típico-ideal que ella fue definida anteriormente.

Esta evolución no pone necesariamente en peligro la estabilidad del gobierno y la gobernabilidad de la democracia en el corto plazo, pero obliga a un manejo y una resolución de los conflictos socioeconómicos y políticos que permita avanzar hacia una mayor equidad en la distribución de los beneficios del desarrollo, la ampliación de la ciudadanía entendida como el derecho a "participar plenamente en la herencia social y a vivir la vida de un ser humano civilizado de acuerdo a los standards que prevalecen en la sociedad" $\mathrm{y}$, por consiguiente, hacia la legitimidad y gobernabilidad a largo plazo de la democracia.

\section{CONCLUSION}

La disminución de la desigualdad en Chile va a depender en definitiva de la convicción, explícita o implícita, de la población del reconocimiento de la igualdad como un valor. Sin embargo, afirmado tan vagamente es fácil llegar a acuerdos. Las dificultades surgen frente a la pregunta de igualdad respecto a qué, a qué precio y mediante qué medios. Como sólo una introducción al tema quisiera hacer algunas sugerencias.

El pensamiento político moderno toma la primacía de los derechos individuales como punto de partida y afirma su primacía por sobre el principio de pertenencia u obligación social.

Dentro de ellos, el primero y fundamento de los demás derechos individuales es el de elegir libremente el propio plan de vida. El discurso normativo iniciado por Hobbes y Locke da prioridad a ese derecho por sobre cualquier obligación social que no sea respetar la libertad de los otros.

La vida en sociedad es una necesidad para los que siguen esta perspectiva en cuanto es útil para ejercer la libertad pero no, como dice Taylor, "una condición esencial al desarrollo de la racionalidad"15.

\footnotetext{
${ }^{i 4}$ Marshall, T. H. 'Class, Citizenship and Social Developnent'. New York: Anchor Books, 1965. p. 78.

is Taylor, Charles, "El Atomismo". 'Derecho y Moral". Editorial Ariel. 1990.
} 
Frente a esa posición está la otra, defendida por Taylor, de que es la intuición de que ciertos individuos tienen ciertas capacidades que debemos valorar lo que lleva a atribuir a ese individuo el derecho a desarrollar esa capacidad. Esta capacidad que sentimos que debe ser respetada es la que fundamenta la atribución de derechos y determina la forma y el contenido de esos derechos. Desde esta perspectiva, el reconocimiento de los derechos humanos se fundamenta en el reconocimiento y respeto que nos merecen ciertas capacidades humanas.

Sintetizando la posición de Taylor en el artículo citado más arriba, admitir la existencia de un derecho es reconocer a una cierta forma de vida que supone ciertas capacidades, Io que, a su vez, lleva a afirmar que es bueno que esas capacidades se desarrollen y que deberíamos ayudar y estimular su desarrollo tanto en nosotros como en los otros.

La consecuencia de esa posición es que el derecho fundamental no es la libertad en sí y por sí misma sino el de poder desarrollar ciertas capacidades reconocidas como humanas, una de las cuales es la capacidad de elegir.

La afirmación del respeto a las capacidades humanas como fundamento de los derechos humanos permite dar un foco a la discusión sobre la igualdad que hace posible la existencia en sociedad. Si se acepta esa posición, se trata de la igualdad de todos los miembros de la sociedad para lograr desarrollar sus propias capacidades. Esta es la posición que ha defendido, desde una perspectiva distinta a la de Taylor, Amartya Sen ${ }^{16}$. Para este autor, la discusión sobre la igualdad es inseparable de la capacidad de los miembros de una sociedad para lograr "funcionamientos" que consideran valiosos. Estos pueden ser tan elementales como estar adecuadamente alimentado, tener buena salud, así como en otras más complejas: respeto de sí mismo, participación en la comunidad, felicidad, etc. La selección y el peso dado a cada uno de esos funcionamientos influye sobre la evaluación de la capacidad de lograr distintos paquetes de ellos.

Tanto en la versión de Taylor como en la de Sen, el concepto "igualdad de oportunidades", en el sentido restringido de igualdad de acceso a diversos medios para el logro de objetivos individuales, es reemplazado por otro: igualdad de capacidades. Para ambos autores, este concepto lleva a dar importancia a las bases sociales de la desigualdad, como son las originadas en las clases, los géneros, la etnia, etc.

Mirar el problema desde la perspectiva de las capacidades obliga a poner la atención en como la estructura social está negando o favoreciendo la libertad fundamental de todas las personas para desarrollar sus capacidades y lleva a plantear la obligación moral de modificar los arreglos estructurales, a fin de hacer a todos igualmente libres para el desarrollo de sus capacidades.

Superar la sociedad de la desigualdad bajo las nuevas formas que ha adquirido a partir del predominio del enfoque neoliberal sobre el hombre y la sociedad requiere también tomar el homo economicus sólo como un tipo ideal necesario para el análisis científico, pero no como un ideal de hombre, es decir, no dar a un artificio heurístico una connotación de deber

\footnotetext{
'Inequality Revisited', Oxford: Clarendon Press, 1992.

Mueller, Dennis C. "Rational Egoism versus Adaptive Egoism as Fundamental Postulates for a Descriptive Theory of Hunian Behavior". 'Public Choice'. Vol. 51, 1986, p. 323.
} 
moral. La búsqueda de la equidad no puede fundarse en la afirmación de Dennis Mueller, en ese momento Presidente del 'Public Choice Society' de que "el egoísmo es el único supuesto esencial de una ciencia descriptiva y prescriptiva de la conducta humana" 17 . Al contrario, ella supone aceptar que el altruismo y la solidaridad son una motivación que ninguna visión realista del comportamiento humano y social puede desconocer sin tener que acudir a imputaciones de motivos imposibles de probar.

La puesta en práctica de un enfoque del desarrollo orientado a la equidad se ve obstaculizada por la aceptación por parte de los decisores políticos. e incluso por muchos científicos sociales, de supuestos neoclásicos acerca del hombre y la sociedad que, en definitiva, no creen que esta sea más que la suma de las partes y se niegan a aceptar la existencia de la solidaridad y al altruismo como motivaciones auténticas y no sólo disfraces del egoísmo. El logro del desarrollo con equidad exige una visión más realista que el dogma pseudo realista neoclásico.

La perspectiva alternativa que se ha planteado aquí sobre el fundamento de los derechos humanos, que sirven de base a la búsqueda de la igualdad y sobre el hombre y la sociedad, requiere de un esfuerzo por cambiar la mentalidad de las elites dirigentes, pero también un esfuerzo paralelo por contrarrestar los intentos de hacer un ideal humano del homo economicus, afirmando la vigencia de la solidaridad y altruismo no solo como un ideal a alcanzar sino como valores presentes y operantes en muchas situaciones de nuestra vida colectiva. Es ese un deber ético fundamental de todos los que no permanecen indiferentes a las inequidades de nuestro desarrollo y nuestra sociedad que, lejos de frenar el desarrollo, puede despertar recursos sociales que una visión individualista tiende a no tomar en cuenta. 